\title{
КОМПЕТЕНТНОСТЬ ПЛАСТИЧЕСКИХ ХИРУРГОВ
}

\author{
Н. Е. Мантурова1, В. В. Кочубей凶, А. В. Кочубей ${ }^{3}$ \\ Российский национальный исследовательский медицинский университет имени Н. И. Пирогова, Москва \\ 2Кафредра факультетской хирургии № 1, лечебный факультет, \\ Московский государственный медико-стоматологический университет имени А. И. Евдокимова, Москва \\ ${ }^{3}$ Кафедра общественного здоровья и здравоохранения, \\ Институт повышения квалификации Федерального медико-биологического агентства, Москва
}

${ }^{1}$ Кафедра пластической, реконструктивной хирургии, косметологии и клеточных технологий, факультет дополнительного профессионального образования,

\begin{abstract}
Отечественная система непрерывного медицинского образования (НМО) не гарантирует ежегодного прогресса профессиональной компетентности у всех ее участников: врачами не предоставляются отчеты о количестве и спектре проделанных операций, оценка компетентности и создание планов индивидуального обучения проводятся ими самостоятельно без участия профессионального сообщества. В этой связи актуальным является изучение компетентности пластических хирургов и объективности ее самооценки. Изучение проводили с помощью очного одноэтапного анкетирования. Анкета содержала два раздела. Первый раздел включал тесты для самооценки компетентности по 9 трудовым функциям пластического хирурга, где 1 означало, что нет опыта, 2 - новичок, 3 - специалист, 4 - знаток, 5 - эксперт. Во второй раздел входили тестовые задания закрытого типа простого одновариантного выбора для объективной оценки знаний респондентов. Правильный ответ оценивали в 1 балл, неверный - 0. В анкетировании приняли участие 162 человека. Средний возраст респондентов был 31,5 \pm 6,9 года, средний стаж работы 4,0 \pm 4,8 года. Для статистического анализа рассчитывали критерии Колмогорова-Смирнова, Манна-Уитни, Краскела-Уоллиса, коэффициент Спирмена, использовали однофакторный дисперсионный анализ (ANOVA), тест Левена, тест Дункана. Статистически значимыми считали значения при р < 0,05. По результатам исследования общий уровень самооценки всех респондентов составил 2,1 \pm 0,92 балла. Обнаружена статистически значимая ( $\mathrm{p}<0,001)$ корреляция стажа с уровнем самооценки $\left(r_{s}=0,72\right)$. Средняя оценка по тестам составила 2,6 \pm 1,76 баллов из 9 максимально возможных. Незначимой оказалась корреляция тестовой оценки со стажем работы $\left(r_{s}=-0,08, p=0,3\right)$ и с самооценкой $\left(r_{s}=-0,006, p=0,9\right)$.
\end{abstract}

Ключевые слова: компетентность пластических хирургов, самооценка компетентности пластическими хирургами, объективность самооценки компетентности

$\bowtie$ Для корреспонденции: Кочубей Валентин Владимирович ул. Делегатская, д. 20/1, г. Москва, 127473; kochoubey@gmail.com

Статья получена: 24.04.2018 Статья принята к печати: 23.05.2018

DOI: $10.24075 /$ vrgmu.2018.023

\section{THE COMPETENCE OF PLASTIC SURGEONS}

\section{Manturova $\mathrm{NE}^{1}$, Kochubey $\mathrm{W}^{2} \otimes$, Kochubey $\mathrm{AV}^{3}$}

${ }^{1}$ Department of Plastic and Reconstructive Surgery, Cosmetology and Cell Technologies,

Pirogov Russian National Research Medical University, Moscow

${ }^{2}$ Department of faculty surgery №1, Faculty of Medicine

Yevdokimov Moscow State University of Medicine and Dentistry, Moscow

s Department of Public health and Healthcare Management,

Institution of Advanced Training FMBA, Moscow

Russian system of continuous medical education does not guarantee professional development of its participants: doctors do not report the number and specifics of the operations performed, self-assess their competence and compile individual professional development plans, and the professional community does not take part in these processes. Therefore, there is a need for accurate assessment of competence of plastic surgeons and objectivity of their self-assessment. We have conducted a study in the form of a single-stage questionnaire filled by the surgeons in person. The questionnaire contained two sections. The first section offered a competence self-assessment table listing 9 plastic surgery specialties; the participants used a 5-point scoring system to state their level, where 1 meant "no experience", 2 — "beginner", 3 — "specialist", 4 — "knowledgeable", 5 - "expert". The second section contained 9 test tasks (closed, univariate) used to objectively assess the level of competence of the participants. Each correct answer added 1 point to the participant's score, wrong answers added nothing. 162 people took part in the survey. The average age of the participants was $31.5 \pm 6.9$ years; average length of service $-4.0 \pm 4.8$ years. Analyzing the data, we applied the Kolmogorov-Smirnov test, Mann-Whitney test, Kruskal-Wallis test, Spearman's coefficient, used ANOVA, Levene's test, Duncan test. The values were considered statistically significant at $p<0.05$. The overall self-
assessment score was $2.1 \pm 0.92$ points. We have discovered a statistically significant $(p<0.001)$ correlation of the length of service with the level of self-assessment $\left(r_{s}=0.72\right)$. The average score for the second section, the tests, was $2.6 \pm 1.76$ points (out of 9). The correlation between the test score and the length of service was insignificant ( $r s=-0.08, p=0.3$ ); same is true for the self-assessment $\left(r_{s}=-0.006, p=0.9\right)$.

Keywords: competence of plastic surgeons, self-assessment of competence by plastic surgeons, objectivity of selfassessment of competence

$\bowtie$ Correspondence should be addressed: Valentin Vladimirovich Kochubey Delegatskaya, 20/1, Moscow, 127473; kochoubey@gmail.com

Received: 24.04.2018 Accepted: 23.05.2018

DOI: 10.24075/brsmu.2018.023 
Согласно законодательству, врач обязан совершенствовать профессиональные знания и навыки путем обучения по дополнительным профессиональным программам [1]. Модернизация отечественной системы медицинского образования нацелена на претворение в жизнь принципа непрерывности повышения квалификации [2]. Для реализации данного принципа создан портал непрерывного медицинского и фармацевтического образования, работа которого поддерживается Центром научно-методического обеспечения перехода на систему непрерывного медицинского и фармацевтического образования Российского национального исследовательского медицинского университета имени Н. И. Пирогова [3, 4]. Портал содержит программь непрерывного образования и образовательные мероприятия, одобренные Комиссией по развитию непрерывного медицинского и фармацевтического образования Министерства здравоохранения Российской Федерации [5]. Таким образом, качество образовательного контента в системе НМО гарантировано. Одновременно портал предоставляет возможность врачу самостоятельно формировать индивидуальный план обучения [3], т. е. повышение квалификации врача зависит от индивидуальных установок врача, его личного стремления к освоению большего спектра профессиональных навыков, а главное объективности самооценки.

На сегодняшний день тестирование при периодической аккредитации является единственным инструментом «отсева» неквалисрицированных специалистов и, безусловно, служит стимулом для повышения квалификации [6]. Но периодическая аккредитация проходит один раз в пять лет и является контрольной точкой допуска врача к специальности. Система НМО в этот пятилетний период не обязует врача к ежегодному повышению компетентности в области профессиональной деятельности, в отличие от зарубежных систем НМО [7-10]. Последние демонстрируют успешность механизмов, используемых для подтверждения ежегодного прогресса профессиональной компетентности, таких как представление в портфолио отчетов о количестве и спектре операций, оценка компетентности профессиональным сообществом и совместное с организацией создание индивидуального плана обучения с выбором тем, обязательных к освоению [11-14].

Целью исследования было изучение компетентности пластических хирургов и объективности ее самооценки по трудовым функциям (ТФ) врача-специалиста в области пластической хирургии.

\section{МАТЕРИАЛЫ И МЕТОДЫ}

В ходе исследования проводили однократное очное анкетирование врачей, имеющих сертисикат по специальности «пластическая хирургия», что являлось критерием включения. Анкета содержала два раздела. Первый включал таблицу для самооценки компетентности по 9 ТФ пластического хирурга от 1 балла («нет опыта») до 5 баллов («эКсперт»). Всего по каждой ТФ было выделено 5 групп: 1 - без опыта, 2 - новички, 3 - «знатоки», 3 «специалисты», 4 - «эксперты».

Среднее значение баллов, выставленное респондентом по всем трудовым функциям, обозначало в настоящем исследовании "общий уровень самооценки». По общему уровню самооценки было выделено 3 группы: низкая самооценка - средний балл от 0 до 2, средняя самооценка - средний балл от 2 до 4, высокая самооценка - средний балл самооценки от 4 до 5 баллов.
Второй раздел содержал 9 тестовых заданий закрытого типа простого, одновариантного выбора для объективной оценки знаний анкетируемых. Тестовые задания были взяты из сборника тестов, используемых при итоговой аттестации резидентов [15]. Правильному ответу присваивали 1 балл, неверный ответ - 0 баллов. Общее количество баллов для отдельного респондента было определено как "общий уровень оценки" с минимальным значением 0 и максимальным значением 9.

В анкетировании приняли участие 162 человека. Анкетирование проводили анонимно. Респонденты указывали возраст, пол и стаж работы в области пластической хирургии.

Средний возраст респондентов составил 31,5 \pm 6,9 лет, средний стаж работы 4,0 \pm 4,8 лет. Среди респондентов было 63 женщины (средний возраст 32,1 1 8,6 лет, средний стаж 4,5 \pm 0,8 лет) и 99 мужчин (средний возраст 31,2 5,5 года, средний стаж 3,7 \pm 0,4 года). По стажу в рамках исследования было выделено 4 группы: стаж 0 лет 14,2\% респондентов, стаж 1-5 лет - 58,0\%, стаж 6-10 лет20,4\%, стаж более 10 лет - 7,4\%. Распределение по возрасту, стажу и вариантам самооценки респондентов является неравномерным ( $p<0,001)$.

Для оценки равномерности распределения использовали тест Колмогорова-Смирнова, отклонение от нормального распределения считал значимым при $\mathrm{p}<0,05$. Для оценки различия между двумя группами использовали критерий Манна-Уитни (U), между множеством групп однофакторный дисперсионный анализ (ANOVA) с одновременным определением гомогенности дисперсий (тест Левена), а также критерий Краскела-Уоллиса (Хиквадрат). Выделение гомогенных групп проводили с помощью теста Дункана. Корреляцию между признаками подтверждали расчетом коэффициента Спирмена $\left(r_{s}\right)$. Статистически значимыми критерии и коэффицциенты считали при $\mathrm{p}<0,05$. Осуществляли расчет средних, стандартных отклонений, процентных долей.

Статистическую обработку данных проводили с использованием программы IBM SPSS Statistics (версия 23).

\section{РЕЗУЛЬТАТЫ ИССЛЕДОВАНИЯ}

По всем ТФ при самооценке большинство пластических хирургов выбрало категорию «нет опыта» (табл. 1).

По всем ТФ доля респондентов уменьшалась по мере повышения их самооценки, за исключением ТФ «хирургия руки и кисти". По этой специальности доля респондентов, выбравших категорию «специалист», превышала долю респондентов, выбравших категорию «знатоки». Свою компетентность в данной ТФ, а также по ТФ «урогенитальная пластика» и «краниофациальная пластика» респонденты оценили наиболее низко.

Общий уровень самооценки всех респондентов составил 2,1 \pm 0,92 балла. По ТФ «Пластика уха» этот показатель достиг 2,2 \pm 1,12 балла, по ТФ «пластика носа» - 2,1 $\pm 1,08$, по ТФ «пластика век» $-2,3 \pm 1,36$, по ТФ «пластика губ» - 2,0 \pm 1,16, по ТФ «пластика груди» $-2,4 \pm 1,32$, по ТФ «урогенитальная пластика» $-1,5 \pm$ 0,96, по ТФ «пластика покровных тканей» - 2,4 \pm 1,24 по ТФ «краниофациальная пластика» - 1,9 $\pm 1,14$, по ТФ «хирургия руки и кисти» - 1,8 \pm 1,09.

Сравнение самооценки компетентности по выделенным группам с различным стажем работы (0 лет, 1-5 лет, 6-10 лет, более 10 лет) показало, что уровень самооценки компетентности по всем ТФ различается (Хи-квадрат 66,9; 
p < 0,001). По мере роста стажа работы увеличивается средний ранг самооценки (табл. 2).

С учетом полученных результатов и факта, что в группах с большим стажем работы уменьшается доля респондентов, оценивающих себя по категории «нет опыта", и увеличивается число лиц, считающих себя «специалистами» и «экспертами", исследовали наличие связи между стажем и уровнем самооценки. Обнаружена статистически значимая ( $p<0,001)$ корреляция стажа с общим уровнем самооценки $\left(r_{s}=0,72\right)$ и уровнем самооценки по отдельным ТФ: «Пластика уха» $r_{\mathrm{s}}=0,64$, «пластика носа» $r_{s}=0,52$, «пластика век» $r_{s}=0,57$, «пластика губ» $r_{\mathrm{s}}=0,66$, «пластика груди» $r_{\mathrm{s}}=0,72$, «урогенитальная пластика» $r_{s}=0,35$, «пластика покровных тканей» $r_{s}=0,62$, «краниофациальная пластика» $r_{s}=0,46$, «хирургия руки и кисти» $r_{\mathrm{s}}=0,42$.

Из общего числа респондентов ни одного правильного ответа на вопросы тестов не дали 7,4\% человек, один верный ответ дали 22,8\%, два правильных ответа - 20,4\%, три - 17,9\%, четыре - 20,4\%, пять - 5,6\%, шесть 3,7\%, девять - 1,9\% респондентов. Доля респондентов, ответивших верно на вопросы тестовых заданий, по ТФ «пластика уха» составила 53,1\%, «пластика носа» - 46,9\%, «пластика век» - 21\%, «пластика губ» - 20,4\%, «пластика груди» - 20,4\%, «урогенитальная пластика» - 24,1\%, «пластика покровных тканей» - 34\%, «краниофациальная пластика» - 32,1\%, «хирургия руки и кисти» - 13\%.

Средний общий уровень оценки респондентов составил 2,6 \pm 1,76 балла. Корреляция «общего уровня оценки» по всем вопросам тестовых заданий со стажем работы отсутствовала $\left(r_{s}=-0,08 ; p=0,3\right)$. Не обнаружена корреляция стажа и частоты правильных ответов по ТФ: «пластика уха» $\left(r_{\mathrm{s}}=-0,03 ; p=0,7\right)$, «Пластика век» $\left(r_{\mathrm{s}}=-0,05\right.$; $p=0,5)$, «урогенитальная пластика» $\left(r_{s}=-0,09 ; p=0,2\right)$, «пластика покровных тканей» $\left(r_{s}=-0,05 ; p=0,5\right)$. Обнаружена статистически значимая, но обратная корреляция стажа и частоты правильных ответов по ТФ «Пластика груди» $\left(r_{s}=-0,2 ; p=0,01\right)$, «краниосрациальная пластика» $\left(r_{s}=-0,05 ; p=0,01\right)$. Только по ТФ «пластика носа» и «пластика губ» имеется значимая слабая прямая корреляция стажа и частоты верных ответов $\left(r_{s}=0,27\right.$; $p=0,001$ и $r_{s}=0,19 ; p=0,02$ соответственно).

Распределение верных ответов в 4 группах, отличающихся по стажу работы, не равномерное (Хиквадрат 12,1; $p=0,007)$.

«Общий уровень оценки» у респондентов, включенных в три сформированные в процессе исследования группы самооценки (низкий, средний, высокий), также значимо не

Таблица 1. Самооценка компетентности пластических хирургов

\begin{tabular}{|c|c|c|c|c|c|}
\hline \multirow{2}{*}{ Трудовая функция } & \multicolumn{5}{|c|}{ Доля респондентов, выбравших категорию } \\
\hline & нет опыта & новичок & знаток & специалист & эксперт \\
\hline Пластика уха & $37 \%$ & $27,8 \%$ & $16,7 \%$ & $18,5 \%$ & - \\
\hline Пластика носа & $38,9 \%$ & $27,8 \%$ & $18,5 \%$ & $14,8 \%$ & - \\
\hline Пластика век & $40,7 \%$ & $22,2 \%$ & $14,8 \%$ & $13,0 \%$ & $9,3 \%$ \\
\hline Пластика губ & $40,7 \%$ & $33,3 \%$ & $13,0 \%$ & $7,4 \%$ & $5,6 \%$ \\
\hline Пластика груди & $33,3 \%$ & $29,6 \%$ & $13,0 \%$ & $14,8 \%$ & $9,3 \%$ \\
\hline Урогенитальная пластика & $68,5 \%$ & $20,4 \%$ & $5,6 \%$ & $1,9 \%$ & $3,7 \%$ \\
\hline Пластика покровных тканей & $31,5 \%$ & $25,9 \%$ & $20,4 \%$ & $16,7 \%$ & $5,6 \%$ \\
\hline Краниофациальная пластика & $50,0 \%$ & $29,6 \%$ & $9,3 \%$ & $5,6 \%$ & $5,6 \%$ \\
\hline Хирургия руки и кисти & $57,4 \%$ & $24,1 \%$ & $5,6 \%$ & $11,1 \%$ & $1,9 \%$ \\
\hline
\end{tabular}

Таблица 2. Общий уровень оценки по стажу и группам самооценки

\begin{tabular}{|c|l|c|}
\hline \multicolumn{1}{|c|}{ Стаж } & \multicolumn{1}{|c|}{ Уровень самооценки } & Средний общий уровень оценки \\
\hline \multirow{2}{*}{0 лет } & низкий & $2,6 \pm 1,64$ \\
\cline { 2 - 3 } & всего & $2,6 \pm 1,64$ \\
\hline \multirow{3}{*}{$1-5$ лет } & низкий & $2,8 \pm 1,61$ \\
\cline { 2 - 3 } & средний & $2,1 \pm 1,48$ \\
\cline { 2 - 3 } & высокий & $1,0 \pm 0,00$ \\
\cline { 2 - 3 } & всего & $2,6 \pm 1,59$ \\
\hline \multirow{3}{*}{$6-10$ лет } & низкий & $2,0 \pm 1,09$ \\
\cline { 2 - 3 } & средний & $3,8 \pm 2,24$ \\
\cline { 2 - 3 } & всего & $3,5 \pm 2,18$ \\
\hline \multirow{3}{*}{ Более 10 лет } & низкий & $0,0 \pm 0,00$ \\
\cline { 2 - 3 } & средний & $1,7 \pm 0,51$ \\
\cline { 2 - 3 } & высокий & $2,0 \pm 0,00$ \\
\cline { 2 - 3 } & всего & $1,3 \pm 0,88$ \\
\hline \multirow{2}{*}{ Всего } & низкий & $2,6 \pm 1,63$ \\
\cline { 2 - 3 } & средний & $2,9 \pm 2,01$ \\
\cline { 2 - 3 } & высокий & $1,5 \pm 0,55$ \\
\cline { 2 - 3 } & всего & $2,7 \pm 1,76$ \\
\hline
\end{tabular}


отличается $(2,6 \pm 1,63,2,8 \pm 2,0,1,5 \pm 0,55$ соответственно, Хи-квадрат 3,3; $\mathrm{p}=0,20)$. В табл. 2 представлен средний балл общего уровня оценки по 4 группам стажа и 3 уровням самооценки.

Незначима корреляция «общего уровня самооценки» с «общим уровнем оценки» $\left(r_{s}=-0,006 ; p=0,9\right)$. По отдельным ТФ распределение верных ответов в 5 группах (без опыта, новички, знатоки, специалисты, эксперты) также было одинаковым: «пластика уха» ( $p=0,36)$, «пластика век» ( $p=0,31)$, «Пластика груди» $(p=0,11)$, «урогенитальная пластика» $(p=0,45)$. По ТФ «пластика носа» $(p=0,0001)$, «пластика губ» ( $p=0,015)$, «пластика покровных тканей» ( $p=0,018)$, «краниофациальная пластика» ( $p=0,002)$, «хирургия руки и кисти» $(p=0,005)$ распределение верных ответов в 5 обозначенных группах было неравномерным.

Тест Дункана позволил выделить гомогенные группы по распределению верных ответов. По ТФ «Пластика носа» одинаковое распределение верных ответов было в группах самооценки «без опыта» $(\mathrm{M}=0,25)$ и "специалисты» $(\mathrm{M}=0,29)(p=0,74)$, а также в группах «знатоки» $(\mathrm{M}=0,60)$ и «новички» $(M=0,76)(p=0,15)$. По ТФ «Пластика губ» не обнаружилось значимого различия между группами самооценки по распределению верных ответов: «без опыта» $(M=0,09)$ и «знатоки» $(M=0,14)(p=0,1)$, отдельно «специалисты» $(M=0,25)$, «новички» $(M=0,33)$, «эксперты»" $(\mathrm{M}=0,33)(\mathrm{p}=0,26)$. По ТФ «пластика покровных тканей» гомогенными по распределению верных ответов были группы «эксперты» $(M=0,00)$ и «новички» $(M=0,21)(p=0,12)$, и группы «без опыта» $(M=0,35)$, «специалисты» $(M=0,44)$, «знатоки» $(M=0,48)(p=0,07)$. По ТФ «краниофациальная пластика» также образовались две гомогенные группы по распределению верных ответов, в одну вошли «знатоки» $(M=0,00)$, «эксперты» $(M=0,00)$, «без опыта» $(M=0,33)$ $(p=0,05)$, в другую - «новички» $(M=0,40)$ и «специалисты» $(\mathrm{M}=0,67)(\mathrm{p}=0,05)$. По ТФ «хирургия руки и кисти» гомогенными по распределению верных ответов стали группы «новички», «знатоки», «эКсперты» $(\mathrm{M}=0,00$ для всех) $(p=0,34)$, и группы «без опыта» $(M=0,20)$ и «специалисты» $(\mathrm{M}=0,33)(\mathrm{p}=0,26)$.

Как видно из представленных данных о гомогенности групп по распределению верного ответа уровень самооценки не соответствует уровню компетентности, определенному с помощью тестирования. Более того, по большинству ТФ в группе «без опыта» частота верных ответов была выше, чем в группе «экспертов» (табл. 3).

По ТФ «Пластика век», где среднее число верных ответов было выше в группе «эксперты», разница статистически незначима $(U=486, p=0,88)$. Только по одной ТФ «пластика губ» средний балл правильных ответов в группе экспертов

Таблица з. Уровень оценки компетентности по результатам тестирования был значимо выше, чем в группе «без опыта» $(U=225$, $\mathrm{p}=0,04)$.

\section{ОБСУЖДЕНИЕ РЕЗУЛЬТАТОВ}

В ходе проведенного анкетирования установлено, что пластических хирургов отличает низкая самооценка уровня компетентности 2,1 \pm 0,92 балл, особенно по ТФ «урогенитальная пластика» (1,5 \pm 0,96), «хирургия руки и кисти» $(1,8 \pm 1,09)$, «краниофрациальная пластика» $(1,9 \pm 1,14)$. Заметим, что по результатам другого нашего исследования [16] именно по данным ТФ отмечался самый низкий процент оперативных вмешательств пластических хирургов.

Однако самооценка компетентности пластических хирургов в большинстве случаев объективна. Уровень объективной оценки компетентности низок: средний балл равен 2,6 \pm 1,76 при максимально возможных 9 баллах.

Обнаруженное повышение уровня самооценки компетентности с увеличением стажа работы, к сожалению, не подтверждается объективной оценкой компетентности. Нет значимой связи уровня оценки со стажем $\left(r_{s}=-0,08\right.$; $p=0,3)$ и уровнем самооценки $\left(r_{s}=-0,006 ; p=0,9\right)$. Хотя по двум ТФ «пластика носа» $\left(r_{s}=0,27 ; p=0,001\right)$ и «пластика губ» $\left(r_{s}=0,19 ; p=0,02\right)$ имеется значимая слабая прямая корреляция стажа и частоты верных ответов, но дальнейшие расчеты при сравнении отдельно групп «экспертов» и «без опыта» или выделении гомогенных групп не подтверждают превосходство по компетентности лиц, имеющих больший стаж. Напомним, что даже по ТФ «пластикагуб», где имелось значимое превышение среднего балла правильных ответов у «экспертов», чем у лиц «без опыта» $(U=225, p=0,04)$, при выделении гомогенных распределений в одну группу с «экспертами» были включены «новички», а категория «без опыта» была объединена со «знатоками». При этом уровни самооценки в целом и по отдельным ТФ значимо коррелируют со стажем работы ( $p<0,001)$.

Тот факт, что респонденты без стажа или с малым стажем работы показали лучший результат по тестовым заданиям, чем респонденты со стажем работы более 10 лет, возможно, объясняется недавним прохождением теоретического курса в ординатуре. Самый высокий результат (3,8 \pm 2,24 балла) у респондентов, имеющих стаж 6-10 лет, свидетельствует об их наибольшей профессиональной активности.

\section{ВЫВОДЫ}

Результаты проведенного исследования, свидетельствующие о низком уровне компетентности пластических хирургов,

\begin{tabular}{|l|c|c|}
\hline \multirow{2}{*}{\multicolumn{1}{|c|}{ Трудовая функция }} & \multicolumn{2}{|c|}{ Среднее число верных ответов в группах } \\
\cline { 2 - 3 } & «без опыта» & «эксперты» \\
\hline Пластика уха & $0,47+0,50$ & - \\
\hline Пластика носа & $0,29+0,46$ & $0,20+0,41$ \\
\hline Пластика век & $0,18+0,39$ & $0,33+0,50$ \\
\hline Пластика губ & $0,09+0,29$ & $0,00+0,00$ \\
\hline Пластика груди & $0,28+0,45$ & $0,00+0,00$ \\
\hline Урогенитальная пластика & $0,26+0,44$ & $0,00+0,00$ \\
\hline Пластика покровных тканей & $0,35+0,48$ & $0,00+0,00$ \\
\hline Краниофациальная пластика & $0,33+0,47$ & $0,00+0,00$ \\
\hline Хирургия руки и кисти & $0,16+0,37$ & \\
\hline
\end{tabular}


несоответствии показателей высокого уровня самооценки компетентности показателям ее объективной оценки, а также о дегрессии уровня компетентности после 10 лет стажа, доказывают состоятельность призывов к ограниченному допуску к реконструктивной пластической хирургии путем дискретного обучения, а также обоснованность заявлений о несовершенстве отечественной системы НМО в отношении самостоятельного составления индивидуального плана обучения.

\section{Литература}

1. Федеральный закон от 21.11.2011 № 323-Ф3 «Об основах охраны здоровья граждан в Российской Федерации». Ст. 73 «Обязанности медицинских работников и фармацевтических работников».

2. Приказ Минздрава России от 02.06.2016 №334н «Об утверждении Положения об аккредитации специалистов".

3. Портал непрерывного медицинского и фармацевтического образования [Электронный ресурс] https://edu.rosminzdrav. ru/o-portale/ Дата обращения 25 декабря 2017.

4. Портал непрерывного медицинского образования. Заместитель главного врача. 2016; 1: 81.

5. Приказ Минздрава России от 18.02.2013 N82 «О Координационном совете по развитию непрерывного медицинского и фармацевтического образования Министерства здравоохранения Российской Федерации».

6. Петрова И. А. Аккредитация медицинских работников: польза и риски. Бюллетень Национального НИИ общественного здоровья имени Н. А. Семашко. 2015; (4-5): 180-6.

7. Кочубей В. В. Непрерывное медицинское образование пластического хирурга в Великобритании. Московский хирургический журнал. 2017; 1: 56-9.

8. Continuing Professional Development (CPD) [Электронный pecypc] https://www.rcseng.ac.uk/careers-in-surgery/surgeons/ practicing-as-a-surgeon/continuing-professional-development Дата обращения 25 декабря 2017.

9. Shojania KG, Silver I, Levinson W. Continuing medical education and quality improvement: a match made in heaven? Ann Intern Med. 2012 Feb 21; 156 (4): 305-8. DOI: 10.7326/0003-4819156-4-201202210-00008

\section{References}

1. Federal'nyy zakon ot 21.11.2011 N 323-FZ «Ob osnovakh okhrany zdorov'ya grazhdan v Rossiyskoy Federatsii», stat'ya 73. Russian.

2. Prikaz Minzdrava Rossii ot 02.06.2016 N334n «Ob utverzhdenii Polozheniya ob akkreditatsii spetsialistov». Russian.

3. Portal nepreryvnogo medicinskogo i farmacevticheskogo obrazovanija Available at: https://edu.rosminzdrav.ru/o-portale Russian.

4. Portal nepreryvnogo medicinskogo obrazovaniya. Zamestitel' glavnogo vracha. 2016; 1: 81. Russian.

5. Prikaz Minzdrava Rossii ot 18.02.2013 N82 «O Koordinacionnom sovete po razvitiyu nepreryvnogo medicinskogo i farmacevticheskogo obrazovaniya Ministerstva zdravoohraneniya Rossijskoj Federacii» Russian.

6. Petrova I. A. Akkreditatsiya meditsinskikh rabotnikov: pol'za i riski. Byulleten' Natsional'nogo nauchno-issledovatel'skogo instituta obshchestvennogo zdorov'ya imeni N.A. Semashko. 2015; (4-5): 180-6. Russian.

7. Kochubey V. V. Neprerynoe medicinskoe obrazovanie plasticheskogo hirurga v Velikobritanii. Moskovskiy khirurgicheskiy zhurnal. 2017; 1: 56 -9. Russian.

8. Conntinuing Professional Development (CPD) [Elektronniy resurs] https://www.rcseng.ac.uk/careers-in-surgery/surgeons/ practicing-as-a-surgeon/continuing-professional-development Data obraschenija 25 dekabrja.

9. Shojania KG, Silver I, Levinson W. Continuing medical education and quality improvement: a match made in heaven? Ann Intern
10. Zolotor AJ, Randolph GD, Johnson JK, Wegner S, Edwards L, Powell $\mathrm{C}$, et al. Effectiveness of a practice-based, multimodal quality improvement intervention for gastroenteritis within a Medicaid managed care network. Pediatrics. 2007; 120: e64450. [PMID: 17766504]

11. Esposito P, Dal Canton A. Clinical audit, a valuable tool to improve quality of care. General methodology and applications in nephrology. World J Nephrol. 2014 Nov 6; 3 (4): 249-55. DOl: 10.5527/wjn.v3.i4.249.

12. GMC. Licence to practise withdrawal appeals ГЭлектронный pecypc] http://www.gmc-uk.org/doctors/14008.asp Дата обращения 25 декабря 2017/.

13. Ericsson KA. Acquisition and Maintenance of Medical Expertise: A Perspective From the Expert-Performance Approach With Deliberate Practice. Acad Med. 2015; 90 (11): 1471-86. [PMID: 26375267].

14. Van de Wiel MW, Van den Bossche P. Deliberate practice in medicine: The motivation to engage in work-related learning and its contribution to expertise. Vocat Learn. 2013; 6 (1): 135-58

15. Enoch S, Jagadeesan J, Jose RM, Chan WY, McGrouth G. Plastic Surgery Exam Questions and Answers: A Guide to the Plastic Surgery exit exam, 2 ed. UK: Doctors Academy Publications, 2012. 498 ps.

16. Мантурова Н. Е., Кочубей В. В., Кочубей А. В. Характеристики деятельности пластических хирургов. Вестник РГМУ. 2017; 6 : $47-51$.

Med. 2012 Feb 21; 156 (4): 305-8. DOI: 10.7326/0003-4819156-4-201202210-00008.

10. Zolotor AJ, Randolph GD, Johnson JK, Wegner S, Edwards L, Powell C, et al. Effectiveness of a practice-based, multimodal quality improvement intervention for gastroenteritis within a Medicaid managed care network. Pediatrics. 2007; 120: e64450. [PMID: 17766504].

11. Esposito P, Dal Canton A. Clinical audit, a valuable tool to improve quality of care. General methodology and applications in nephrology. World J Nephrol. 2014 Nov 6; 3 (4): 249-55. DOI: 10.5527/wjn.v3.i4.249.

12. GMC. Licence to practise withdrawal appeals [Elektronniy resurs] http://www.gmc-uk.org/doctors/14008.asp Data obraschenija 25 dekabrja.

13. Ericsson KA. Acquisition and Maintenance of Medical Expertise: A Perspective From the Expert-Performance Approach With Deliberate Practice. Acad Med. 2015; 90 (11): 1471-86. [PMID: 26375267]

14. Van de Wiel MW, Van den Bossche P. Deliberate practice in medicine: The motivation to engage in work-related learning and its contribution to expertise. Vocat Learn. 2013; 6 (1): 135-58.

15. Enoch S, Jagadeesan J, Jose RM, Chan WY, McGrouth G. Plastic Surgery Exam Questions and Answers: A Guide to the Plastic Surgery exit exam, 2 ed. UK: Doctors Academy Publications, 2012. 498 ps.

16. Manturova N. E., Kochubey V. V., Kochubei A. V. Harakteristiki deyatel'nosti plasticheskih hirurgov. Vestnik RGMU. 2017; 6: 47-51. 